\title{
When Suicide Happens in the Medical Community
}

\author{
Mack Lipkin
}

Bellevue Hospital Center, Primary Care Internal Medicine Residency Education Program, Division of General Internal Medicine and Clinical

Innovation, New York University School of Medicine, New York, NY, USA.

When suicide happens close to doctors, students, and faculty, to our families, friends, colleagues, students, residents, fellows and patients, it challenges us as individuals and as members of institutions that seek to provide safety and support. The US suicide rate has increased and suicide remains difficult to predict or to prevent despite its association with depression and addiction. It is less common in medical students and residents than in the general, age-matched population but generates troubling, complex aftershocks for us. Individuals react according to their history and style, through stages, psychological defenses, and difficult affects. Grief, shock, anger, denial, and guilt are prevalent. People responding to a close suicide seek information, asking "why", "what if" and "if only", despite the speculative nature of attempting to understand what happened and why. Nearby suicide may be more challenging for us in the medical profession because the helplessness it evokes undermines our sense of omniscience and omnipotence. Thus, we engage in retrospection and a search for preventive interventions that may or may not be evidence based, salutary, or healing.

$\mathrm{J}$ Gen Intern Med 34(2):317-9

DOI: $10.1007 / \mathrm{s} 11606-018-4734-x$

(c) Society of General Internal Medicine 2018

uicide happens often enough to touch each of us. It may $\checkmark$ kill our colleagues, friends, patients, or relatives. It challenges us as doctors, healers, and people, as well as our institutions seeking answers and safety. The suicide rate increased nearly 30\% between 1999 and 2015, becoming the 10th leading cause of death, 44,193 lives in 2015. ${ }^{1}$ Several medical community suicides happened in New York 2 years ago and two in 5 days recently.

These are some sample suicides and attempts that touched my life.

My last week of internship, a beloved and admired fellow intern made a serious suicide attempt, survived, and left the program. It was sad, shocking, inexplicable, dissonant, disorienting, and frightening.

During residency, a dear friend shot herself. I agonized that by being overcommitted to my patients, I had neglected my friend, and she had not let me help. I came to understand that it is impossible to know what actually happened when a person

Received September 11, 2018

Revised September 17, 2018

Accepted October 26, 2018

Published online November 13, 2018 kills herself, unless you were there in her head at the time. So, now, while I seek to understand, I try not to speculate.

Four years later, my first outpatient suicided, a charming, accomplished, bipolar woman my age. I had treated her biopsychosocially for 3 years, collaborating with her psychiatrist. She was reestablishing a more positive sense of self. After her overdose, I obsessed: why did not she let me help? What did I miss? What could I have done differently? Another psychiatrist with whom I reviewed her case, listened, reflected, consoled, and said, "...bad things happen to good doctors."

As with me, suicide likely will hit close to you. When suicide happens among doctors and medical learners, the death and loss leave us hurt both by the tragedy and by helping failure. We wonder what is wrong with us and our work, what did we fail to do, why did not we know, why did not we do better?

\section{HOW OFTEN DOES IT HAPPEN?}

Physicians, in general, suicide almost twice as often as the general population. Yet, suicide is less common in the medical resident community than in the general population. The suicide rate for male residents is 5.09/100,000 (general population rate, 21.7) and for females is $1.88 / 100,000(5.15 / 100,000$ general population). ${ }^{2,3}$ In the medical community when suicide happens, a human tendency emerges: to blame our problem (a suicide) on our condition (overworked medics) which may be wrong even when the environment is obviously unhealthy.

We cannot usefully detect suicidality clinically. A metaanalysis of 365 studies concluded, "Based on the existing literature, all STB [suicidal thoughts and behaviors] risk (and protective) factors are weak and inaccurate. This general pattern has not changed over the past 50 years ..." 4 The United States Preventive Services Task Force wrote, "The current evidence is insufficient to assess the balance of benefits and harms of screening for suicide risk in adolescents, adults, and older adults in primary care," so they grade recommendation of suicide risk- screening "I" [insufficient evidence]. ${ }^{5}$ Except for treatment of depression in the short run, we have little power clinically to prevent suicide. These facts frustrate as national rates escalate and headlines amplify celebrity suicides.

We know and worry that suicides can cluster and be contagious. In particular, males, persons with depression or addiction, those who are impulsive by personality, who have thought about it seriously, or who seek retribution or attention 
may be vulnerable to a suicide's rip tide. So, our leadership offers space and time and urges such people as we recognize to come talk, obtain care, avoid social isolation, and stay sober.

\section{HOW PEOPLE RESPOND}

When suicide happens nearby, an individual's response has many determinants. The best predictor of future response is prior response, but for many medical learners, this may be their first close brush with the death of someone like themselves. Others will have lost close persons, or have themselves made attempts in the past, heightening their vulnerability, but guiding us in helping them.

Persons responding to a suicide go through individual sequences of stages, experience varied and personal feelings, and defend psychologically according to their history, culture, character, and personality style. There might be utility for those attempting to help themselves or others to recognize some of the common tendencies.

\section{ON STAGES}

There is no evidence-based description of stages of response to suicide, so what follows draws from descriptions of response to death and to trauma. The value of thinking of stages is they aid those trying to be helpful to better consider and respect their subject's adjustment, discovered through active listening. For example, when someone is in shock, the best-intentioned discussion of how to heal will likely be futile and possibly alienating. Cultures and religions have evolved their rituals accordingly. Grief ceremonies such as wakes occur in most cultures and religious communities and function to give the wounded time for mourning and grieving, to adapt, normalize, and ritualize grief and emotional expression, and prevent isolation - permitting but not pushing for resolution, while suggesting life will go on.

Grief stages are neither linear (first you are angry, then you bargain), nor exclusive. ${ }^{6}$ For example, one may be denying affectively, feeling angry systemically, guilty as a helper, and bargaining in choosing how to act. Helpers need to assess and reflect at a granular level, eliciting and interpreting where is this person, at this moment, in this dimension. Nor are stages distinct, reliably associated with specific affects, or set in number. Kubler Ross named five stages (denial, anger, bargaining, depression, and acceptance), ${ }^{7}$ the stages of grief model names seven, adding more nuance to recovery, traumatologists have others. ${ }^{8}$ In our recent experiences, prominent stages included shock, anger, and denial.

Shock comes first for many, manifested by feeling emotionally numb, derealized (this is like a movie), or depersonalized (I am not experiencing this). Memories flood, and it can be difficult to distinguish them from the present (hearing the person's voice, seeing them around corners), together with wanting to flee. This can be frightening and painful. Self- protection mechanisms mobilize. When I learned my first patient had suicided, for 2 months, I morbidly ruminated about "what if only's," self-blame, and quitting medicine.

Anger, while common, is fraught in the setting of suicide because of the discomfort of where to direct it. Usual targets include oneself (why did not I know, help, prevent this?), the deceased (how could she, why did not he reach out?), friends, or the system. Not to have been able to help especially frustrates. Some angry reactors want to take action, form committees, reform policies, consult with outsiders. Since there is plenty to be angry about in modern medical environments, responders can get stuck at the anger stage and resultant activities can be nonproductive or futile.

Denial serves to numb debilitating pain. It can be about the feelings, the reality, or the wished-for alternatives. Our ultimate ubiquitous helplessness, in the face of mortality, is backlit by suicide. So, when suicide happens, expect elaborated denial and extensive, reasonable post hoc prescriptive activity. We should educate supervisors, peers, ourselves. We should make mental health services more available, remove or reduce the toxic elements of our environment, know how every person is doing, and decrease burnout while increasing resilience.

\section{PSYCHOLOGICAL RESPONSES}

When something important and difficult happens, it is natural to try to understand it, to want to take action in order to prevent recurrence, to enhance personal safety, and to restore one's sense of competence, and control. Inevitable sensible questions like why or what was going on morph quickly into speculation seeking to make sense of an unfathomable final act, built on half-truths. Such irresistible ruminating entraps. Why is followed by what if. As the answer to why is built on guesses, what if is woven from wishfulness. When my friend shot herself, I went over and over and over if only I knew, if only she called, if only I were omniscient in service of my omnipotence. Such plaintive hopes push out the pain, and probably are both unavoidable and healthy in the short run.

Sometimes people choose to implement preventive measures, since action counters helplessness. A helpful, evidencebased guide to things to do is the CDC's Preventing Suicide: A Technical Package of Policy, Programs, and Practices..

Guilt pervades medical discussions of a colleague's suicide. Its currency is the two-headed coin of failed omniscience- - I should have known - and omnipotence - if only I were more aware, perceptive, able to read minds. Guilt implies control: if I was responsible but failed, then I am still in charge and not helpless. Personally, since I do not know how to assuage my guilt, I strive to tolerate it. Similarly, rumination can reflect unwillingness to let go and the need to remain in the presence of the lost person. It may heighten vulnerability by emphasizing the half-empty parts of one's existence and entraining negative affect. 


\section{FEELINGS AND CARING}

Suicide elicits many hard feelings like grief, sadness, helplessness, hopelessness, anger, and fear. We need to cope with these both personally and publicly, in groups, ad hoc and established meetings, and rituals.

There are not actionable data here, only experience. Over many decades, a few phenomena have recurred. In our primary care internal medicine residency, I facilitate weekly psychosocial rounds for all residents (range 4-26) not on ward services which have evolved into an established safe, confidential, intimate, and provenly caring environment for discussing their priority, non-biotechnical issues. So, when suicides recently happened close by, the residents felt able to use the group personally and helpfully (they said) to grieve and process. Guilt, so personal and shameful, is especially defanged when recognized as universal. In contrast, feedback from residents about the larger scale ad hoc, institutional meetings was less positive due to lack of established trust and safety, leadership by outsiders, and occurring when residents were still in shock or denial.

Because we recognize how varied optimal coping can be for individuals, in addition to our psychosocial rounds and added ones by request, our approach has been systematically to be aware and informed about each person, in order to ensure that our caring and support is understood, felt and trusted. We hope those at high risk will benefit by walking through our open doors.

\section{OUR SISYPHEAN ROCK}

How to grieve actively, yet not reinforce negative anxious and depressive affects, is a quandary. We try to listen to and attempt to remedy the valid, mutable concerns and toxicities. We talk seriously about what to do when we hear about suicidality with patients - removing violent means, initiating appropriate depression and addiction treatment, teaching selfassessment and making plans for when and how to get help, making contracts with patients to call if in trouble, making sure, and double checking, we have done all we could have done.

Camus argued, "There is but one truly serious philosophical problem, and that is suicide." ${ }^{10}$ Clinically, with suicide, our urgency fuels our futility. We suffer with helplessness when someone we care about chooses death over life. At the end of a long life, when debility and agony are all that remain, I struggle to accept and respect a patent's choice when to die; and I do not abandon someone I deeply care for to be alone with such a choice. When someone young chooses death, I experience the choice as tragic and suffer my failure to perceive or help. For the younger Camus, ${ }^{10}$ not to suicide set revolt against absurdity. When older and more desperate, he found meaning in solidarity and humanism against our helpless condition. ${ }^{11}$ When suicide happens, even though we feel helpless, we can help each other, strive to do better, and trudge back up, alerted, ever unready, for the next time.

Acknowledgments: The author deeply appreciates the thoughtful and substantive comments on and improvements to this manuscript by Maryaline Catillon, Katherine O. Chelby, John F. Crow, Carolyn Drake, Marc Frader, and Sondra Zabar and he thanks the wise, courageous, and supportive residents in the NYU Primary Care Residency program.

Corresponding Author: Mack Lipkin, Bellevue Hospital Center, Primary Care Internal Medicine Residency Education Program, Division of General Internal Medicine and Clinical Innovation, New York University School of Medicine, 550 First Avenue, OBV CD604, New York, NY 10016, USA (e-mail: macklipkin@gmail.com).

\section{Compliance with Ethical Standards:}

Conflict of Interest: The author declares that he does not have a conflict of interest.

\section{REFERENCES}

1. Stone DM, Simon TR. Fowler KA, Kegler SR, Keming Y, Holland KM, Ivey-Stephenson AZ, Crosby AE. Vital Signs: Trends in State Suicide Rates - United States, 1999-2016 and Circumstances Contributing to Suicide - 27 States, 2015. MMWR. 67; No. 222018.

2. NIMH: https://www.nimh.nih.gov/health/statistics/suicide.shtml accessed October 16, 2018

3. Yaghmour, N A., Brigham, TP, Richter, T, Miller, RS, Philibert, I, Baldwin, DC, Nasca, TJ. Causes of Death of Residents in ACGMEAccredited Programs 2000 Through 2014: Implications for the Learning Environment. Academic Medicine: 92: 976-983.

4. Franklin JC, Ribeiro JD, Fox KR, Bentley KH, Kleiman EM, Huang X, Musacchio KM, Jaroszewski AC, Chang BP, Nock MK. Risk factors for suicidal thoughts and behaviors: A meta-analysis of 50 years of research. Psychol Bull. 2017;143(2):187-232.

5. United States Preventive Services Task Force. Suicide risk in adolescents, adults and older adults: screening. 2014 https://www. us preventiveservicestaskforce.org / Page / Document / UpdateSummaryFinal/suicide-risk-in-adolescents-adults-and-olderadults-screening?ds=1\&s=suicide $\% 20$ screening accessed October 16 , 2018

6. Maciejewski PK, Zhang B, Block SD, Prigerson HG. An empirical examination of the stage theory of grief. JAMA. 2007;297(7):716-23.

7. Kübler-Ross E. On death and dying. Simon and Schuster, 1997.

8. Brown CR, Andrews B, Valentine JD. Metanalysis of risk factors for posttraumatic stress disorder in trauma-exposed adults, J Consulting and Clinical Psychology 68:748. 2000.

9. Center for Disease Control and Prevention. Stone D, Holland K, Bartholow B, Crosby A, Davis S, Wilkins N. Preventing suicide: a technical package of policy, programs, and practices. 2017. https://www.cdc.gov/ violenceprevention/pdf/suicidetechnicalpackage.pdf accessed October 16,2018

10. Camus, A. The myth of Sisyphus and other essays. Trans. O'Brien J. New York: Vintage, 1991: p 3.

11. Camus A. The plague. Trans Gilbert S. New York: Vintage, 1991: p. 308 